\title{
Presente, Memória e Autoritarismo: Agir Politicamente?
}

Eduardo Zayat Chammas, Gabriel Ferreira Zacarias, Tiago Machado de Jesus

\section{Resumo}

O artigo tem como ponto inicial a questão das possibilidades de ação política na contemporaneidade, sobretudo no segmento da juventude. Identificamos, em nossa realidade presente, um entrecruzamento temporal no qual a memória produzida acerca dos anos de estado autoritário determina a ação política atual, ou seja, dos anos de "abertura". Levantamos, assim, três questões centrais: O que é este tempo presente?; Como é possível elaborar a memória de um evento traumático?; Quais as relações entre o estado autoritário e o estado de direito? Realizamos, então, um primeiro estudo interdisciplinar, tentando mobilizar os campos da filosofia, da sociologia e da crítica literária para dar conta de problematizar uma história que é entendida como zona de intersecção entre passado e presente.

Palavras-chave: história, memória, política, trauma. 


\section{Introdução}

Como agir politicamente no mundo contemporâneo? Sem descartar esta pergunta ampla, mas considerando que qualquer tipo de resposta a ela seria, nestes termos, evasiva ou panorâmica demais. Foi assim que procedemos rumo a uma sintonia fina que pudesse fechar o foco desta questão mais ampla que continua a nos perturbar. Nesse sentido, foi a nossa própria experiência que guiou nossos passos. Ou seja, a seleção ora em operação busca contemplar algumas das questões surgidas a partir do fazer político dentro do movimento estudantil e, mais precisamente, no nicho universitário que atualmente trava uma luta desigual contra o governo do Estado de São Paulo pela manutenção da universidade pública, em geral, e da Universidade de São Paulo, especificamente. Isto sem desconsiderar o estatuto próprio de nossa contemporaneidade. Em outras palavras, desejamos construir uma abordagem que procura considerar que o fazer político do movimento estudantil aparece inserido em um contexto social maior, mas que possui suas especificidades, áreas de atuação e uma forma peculiar de agir.

Assim, logo no início de nossas investigações, percebemos que as referências do movimento estudantil, como não poderiam deixar de ser, remontam ao período da resistência à ditadura militar e, especialmente, às lutas travadas em I968 - marco emblemático do movimento estudantil no mundo todo.

Precisamente, seria a condição de acesso a estas referências, que pautam a organização e a forma de atuação do movimento estudantil até os dias de hoje, o objeto primeiro deste artigo. Todavia, julgamos, neste momento, mais prudente, sem esquecer nossa motivação inicial, partir para um passeio por textos que talvez pudessem nos ajudar, desde que devidamente lidos, a entender a maneira pela qual a memória é produzida, recebida e reinventada na sociedade contemporânea. Nesse sentido, busca-se considerar todas as conseqüências que tal apropriação engendra. Assim, a escolha dos textos aqui apresentados obedece a um imperativo interdisciplinar que procura, nos limites do possível, mobilizar os campos da filosofia, da sociologia e da crítica literária para dar conta de problematizar uma história que é entendida como zona de intersecção entre passado e presente.

O primeiro texto escolhido é um artigo de Irene Cardoso, professora aposentada do departamento de sociologia da USP. Ali, tomamos de empréstimo um vocabulário habilmente organizado pela autora, com vista à possibilidade de constituição de um léxico que nos permitisse pensar e falar sobre uma crítica do presente numa sociedade que cada vez mais se pauta pela busca do consenso apaziguador das tensões do real. 
Já o texto de Márcio Seligmann-Silva traz à baila a questão das memorizações, ou seja, trata das condições de produção de índices de um passado. Neste caso, trata-se de um tipo especial de memorização. É aquela formada sob condições traumáticas, que testemunham situações-limite, na qual a morte é presença constante e o indizível faz suas incursões, abalando as condições perceptivas e formulações lingüísticas até então válidas.

A terceira leitura está baseada no último livro do filósofo Giorgio Agamben, intitulado Estado de exceção. Ali, o autor busca dar conta de uma arqueologia do estado de direito que acaba por revelar que sua mola propulsora são os dispositivos legais que suprimem seu próprio estatuto. Em nossa leitura, este texto tem como objetivo maior estipular um parâmetro para nossa compreensão do atual contexto político pós II de setembro e suas relações com o passado recente.

\section{Por um Presente do Pretérito e Vice Versa}

Pelo menos desde Marc Bloch, os historiadores sabem que a principal preocupação de seu ofício é o tempo presente. Neste contexto, o passado perde seu estatuto ontológico positivo como algo dotado de um Ser que poderia, através de um trabalho paciente de um historiador-cientista, ser restaurado tal como foi. A partir da revolução na maneira de conceber o tempo, que teve lugar na primeira metade do século Xx, a história não é senão doação de sentido através de exigências do tempo presente. É o presente que organiza e determina o sentido do que é recuperado no passado. Dito em poucas palavras, é uma reflexão sobre a natureza desta temporalidade complexa com suas conseqüências para o indivíduo produtor de memorizações, tal como foram pensadas ao longo do século Xx, que orientará as reflexões a seguir. Para tanto, elegeu-se, no curso dos nossos estudos, um pequeno artigo da socióloga Irene Cardoso ${ }^{1}$ como base de apoio para estas considerações. Tal escolha, por certo, não é fruto do acaso. Ao contrário, ela já encaminha nossa visada em direção àquilo que a própria autora entende como a construção da possibilidade de uma crítica do presente que, em última instância, seja capaz de pôr à prova o próprio estatuto do tempo presente.

Desta forma, é plenamente compreensível que Irene Cardoso abra seu texto da seguinte maneira:

I Irene Cardoso. "História, memória e crítica do presente". In: Para uma crítica do presente. São Paulo: Editora 34, 200I, pp.15-40. 
Não é indiferente, para a interpretação, o modo de trabalhar o tempo quando se trata de reconstruir um acontecimento histórico que depende da relação da memória com o esquecimento e do viés que essa reconstrução toma a partir de uma problematização cujo lugar é o presente. ${ }^{2}$

Aqui, a autora não esconde suas cartas; ao contrário, já de saída, clama por um conceito de história em sintonia com uma crítica radical e de amplo alcance que a historiografia do século XX não cansou de repetir. Trata-se dos desdobramentos atinentes a uma crítica radical ao conceito de tempo entendido de forma linear, cujo desenvolvimento está baseado na noção de progresso cunhada ao longo de todo século XIX.

Poderíamos mapear à exaustão esta crítica ao modelo temporal linear. Todavia, por ora, parece suficiente evocar as célebres "Teses sobre o conceito de história” de Walter Benjamin, pois, neste texto composto em I940, ele já assinala uma posição muito clara, de amplas conseqüências e muito influente em relação ao conceito de tempo que, doravante, deveria guiar o historiador ${ }^{3}$ :

A história é objeto de uma construção cujo lugar não é o tempo homogêneo e vazio, mas um tempo saturado de "agoras". Assim, a Roma antiga era para Robespierre um passado carregado de "agoras", que ele fez explodir do continuum da história. (...) O materialista histórico não pode renunciar ao conceito de um presente que não é transição, mas pára no tempo e se imobiliza. Porque esse conceito define exatamente aquele presente em que ele mesmo escreve a história. ${ }^{4}$

Em suma, pode-se observar nestes dois trechos da obra benjaminiana os desdobramentos possíveis de uma certa forma de encarar o tempo. Fica claro, nestes excertos, que o conceito de tempo, ora em operação, engendra inúmeras temporalidades. O fluxo do tempo passa a ser entendido como uma via de múltiplas possibilidades, no qual tanto o passado quanto o presente se encontram numa relação de interdependência mútua. Tal diagnóstico deve ser efetuado no momento em que os suportes de memórias, as memorizações, são tensionadas a

2 Irene Cardoso. "História, memória e crítica do presente". In: Para uma crítica do presente. São Paulo: Editora 34, 200I, p.I5.

3 Para uma visão panorâmica da teoria da história no século Xx e de sua crise, $c f$. Jorge Luis Grespan.

"O lugar da história em tempos de crise" . In: http://www.anpuh.uepg.br/historia-hoje/vol2n5/Jorge.htm

4 Walter Benjamin. "Sobre o conceito de história" In: Obras escolhidas., v. I, 3. ed. São Paulo: Editora Brasiliense, I987, pp.229-230. 
partir do par lembrança/esquecimento, responsável por esse esfacelamento da temporalidade linear ${ }^{5}$.

Portanto, o que está em jogo é a necessidade de estabelecer uma relação diferencial que possa tirar todas as conseqüências de um conceito de tempo não cronológico.

Neste ponto, cabe detalhar, com um pouco mais de vagar, os instrumentos conceituais que podem ser mobilizados para a realização desta tarefa, sempre tendo como base o texto sintético de Irene Cardoso.

Um elogio ao anacronismo

O texto em estudo pretende reunir esforços para a construção de uma plataforma móvel que seja capaz de garantir uma visada do passado a partir de múltiplos pontos de vista. Todavia, não propõe a exaustão de qualquer destes pontos de vista, uma vez que tem plena consciência de seu próprio movimento, sabendo que seu olhar porta um viés "anacrônico" responsável pela produção de diferenças. Trata-se, pois, de um anacronismo consciente, na medida mesma em que sabe que está inserido em um presente complexo, frágil, pronto para ser estilhaçado e apropriado pelo historiador.

Assim, segue-se a via de múltiplos sentidos, conforme sugerida por Walter Benjamin. O passado, tomado como um processo de memorização, porta sua diferença. Esta, por sua vez, é percebida somente através de um presente mobilizado por uma consciência que tem clara para si sua própria complexidade, seus próprios problemas.

Em outras palavras, o que parece estar em operação aqui são os desdobramentos do movimento diferenciador capaz de constituir um problema histórico.

\section{A atualidade}

Neste contexto, observa-se o aparecimento de pelo menos dois conceitos que se destacam no movimento próprio a este fazer. O primeiro deles, cuja formulação se inspira nos trabalhos tardios de Derrida e Foucault, atende pelo nome de atualidade:

5 Tal como evidenciado na obra magistral de Marcel Proust: sua Recherche, foi comentado por Walter Benjamin nos seguintes termos: "A eternidade que Proust nos faz vislumbrar não é a do tempo infinito, e sim a do tempo entrecruzado. Seu verdadeiro interesse é consagrado ao fluxo do tempo sob sua forma mais real e, por isso mesmo, mais entrecruzada, que se manifesta com clareza na reminiscência." Walter Benjamin. "A imagem de Proust". op cit., p.45. 
Esta implica uma temporalização do presente, que não é dado, mas construído por uma problematização, ou seja, trata-se de reconhecer ou distinguir entre outros um certo elemento desse presente. Nesse sentido, a atualidade é o presente como diferença histórica. A atualidade constitui-se, então, como uma alteridade em relação ao passado e ao próprio presente. Caracteriza-se como um movimento de disjunção desse presente, de uma não contemporaneidade dele em relação a si próprio. ${ }^{6}$

Aqui, o historiador assume uma posição ativa e construtiva na elaboração de seu conjunto de problemas que parte de uma temporalidade, entendida como o seu presente, que ele próprio, no entanto, destaca e diferencia.

Entrementes, a operação do historiador construtivista remete imediatamente a uma outra relação diferencial, àquelas relativas às memorizações, ou seja, aos elementos responsáveis pelo tensionamento dos suportes da memória, dos registros de um passado.

\section{Acontecimento}

O historiador, neste sentido, olha para o passado e vê nele um problema. Ele, a partir de seu presente-problema, elabora uma diferença irremediável do passado com ele mesmo. Algo que, lógica argumentativa do texto, remete ao conceito de "acontecimento histórico":

(...) o acontecimento histórico, a partir do recorte da memória, na sua relação com o esquecimento, que, ao fazer surgir constelações de sentido que não coincidem imediatamente com nenhum "fato histórico específico", pode reunir significados entrecruzados por temporalidades históricas diversas e distanciadas do ponto de vista cronológico. A memória tensionada pelo esquecimento pode se constituir num movimento que anacroniza significados de um passado ao torná-los presentes pela rememoração. ${ }^{7}$

Mais uma vez, constata-se que o pleno funcionamento desta visada depende de uma certa maneira de observar a realidade, de divisar as múltiplas temporalidades que cercam o cotidiano, só que, desta vez, com os olhos voltados às formas de aparecimento do passado. Assim, "acontecimento histórico", tal como entendido no trecho acima citado, é aquele que contém um

6 Irene Cardoso. "História, memória e crítica do presente". In: Para uma crítica do presente. São Paulo: Editora 34, 200I,p. I6.

7 idem. ib. p.22. 
significado que nega o seu próprio tempo, que age como que explodindo o continuum da temporalidade dominante, sendo, portanto, algo "único e agudo".

Tal perspectiva não pode, portanto, produzir, segundo as razões acima expostas, uma narrativa linear e ordenadora. Em suma:

A perspectiva de reconstrução histórica que parte da atualidade e faz do acontecimento o seu núcleo orientador da interpretação não o dilui no interior dos processos totalizantes, mas, pelo contrario, faz dele o que seria o efetivamente singular na história, no sentido do que é "único e aguado", como expressão de uma diferença histórica constitutiva de uma problematização. ${ }^{8}$

\section{Processos de memorização}

Para dar conta deste imperativo, convém apontar que os processos de memorização aos quais tem acesso o historiador, a partir de seu presente-problema, são também frutos de condições histórico-sociais precisas aos quais os sujeitos respondem das mais variadas maneiras. Ou seja, o historiador seria responsável por percorrer estes caminhos, recortando-os, sem que para isso precise seguir em linha reta.

Assim, é possível pensar, à guisa de exercício, numa analogia aproximativa com a experiência clínica legada pela psicanálise, principalmente quando ela trata das regressões patológicas que marcariam a conduta de pacientes neuróticos. Pois, sabe-se que, nestes casos, o passado ao qual se retorna é, fundamentalmente, o passado imaginário das substituições fantasmáticas:

a doença tem por conteúdo o conjunto das reações de fuga e de defesa através da qual o doente responde à situação na qual se encontra; é a partir deste presente, desta situação atual que se deve compreender e dar sentido às regressões evolutivas que aparecem nas condutas patológicas; a regressão não é apenas uma virtualidade da evolução, ela é uma conseqüência da história. ${ }^{9}$

Posto de outra forma, a regressão é um processo vinculado a conflitos que se desenrolam no campo de interações do sujeito com a configuração de seu presente-problema. Assim, analisar os mecanismos de defesa significaria ana-

8 Irene Cardoso. "História, memória e crítica do presente". In: Para uma crítica do presente. São Paulo: Editora 34, 200I, p.22.

9 Michel Foucault. Doença mental e psicologia, Rio de Janeiro: Tempo Brasileiro, I975, p. 43. 
lisar o modo com que o sujeito reproduz e reconstitui sua história a partir de conflitos próprios à sua situação presente. Significaria compreender como ele mobiliza a regressão, o isolamento, a introjeção, a projeção, a anulação retroativa, entre outros expedientes, a fim de dar conta de contradições nas quais ele se enredou em seu presente ${ }^{\text {IO }}$.

\section{As Situações Traumáticas}

Os estudos sobre as chamadas narrativas de testemunho são, para nossos propósitos, um campo repleto de sugestões, pois elas se definem como uma junção simultânea entre necessidade de rememoração e sua virtual impossibilidade, uma vez que se estruturam a partir de um excesso de realidade oriundo de um evento traumático que desfaz a estrutura perceptiva do sujeito, testemunhando uma falta irreparável: a cisão entre a linguagem e o acontecimento, a impossibilidade mesma de recobrir o vivido com o auxílio da linguagem. O testemunho, bem entendido, não seria propriamente a narração de fatos violentos, mas seria antes índice da resistência à compreensão dos mesmos. Neste sentido, para iniciarmos nossas leituras sobre este tema, elegemos como texto base uma coletânea de textos editados por Márcio Seligmann-Silva ${ }^{\mathrm{II}}$.

A matéria da qual as narrativas de testemunho são formadas advém do "trauma", palavra que deriva do grego, cuja significação primeira é "ferida". Tal evento não é outro senão a Shoah, palavra que alude ao genocídio perpetrado pelos nazistas durante a segunda guerra mundial, talvez a maior das catástrofes num século que foi pródigo em multiplicá-las quase ao infinito.

O trauma, com efeito, tal como definido por Freud, é uma experiência que encontra o sujeito de tal forma que a cadeia de eventos formadora de uma dada situação não pode ser total e imediatamente assimilada por ele. É como se as suas estruturas perceptivas, sua própria linguagem se tornasse, de repente, incapaz de cercar e limitar aquilo que acontece diante dele, então o sujeito falha ao

IO Esta parte de nossa pesquisa deve muito ao professor Vladimir Safatle do Departamento de Filosofia da Faculdade de Filosofia, Letras e Ciências Humanas que, ao disponibilizar as anotações de suas aulas do curso ministrado no segundo semestre de 2006, forneceu uma base sem a qual estas considerações não poderiam ter sido feitas.

II Márcio Seligmann-Silva. História, memória, literatura. O testemunho na era das catástrofes. Campinas: Editora da Unicamp, 2003. 
tentar dar uma forma ao real. Daí o fato de que o traumatizado sempre retorna ao evento traumático, pois a incapacidade de assimilar o choque, via estrutura perceptiva da consciência, determina a repetição, o constante retorno alucinatório à cena do trauma. Assim, é possível notar que a narrativa de testemunho lida com experiências limites que põe à prova, de maneira radical, o próprio estatuto do sujeito, pois sua construção monolítica, frente ao trauma, desaba e precisa ser refeita a partir de seus escombros:

Aquele que testemunha sobreviveu - de modo incompreensível - à morte: ele como que a penetrou. Se o indizível está na base da língua, o sobrevivente é aquele que reencena a criação da língua. Nele, a morte - o indizível por excelência, que a toda hora tentamos dizer - recebe novamente o cetro e o império sobre a linguagem. O simbólico e o real são recriados na sua relação de mútua fertilização e exclusão. ${ }^{12}$

A questão que nos propomos, neste delicado terreno, é da seguinte ordem: quais são os instrumentais que tornam possível a leitura de tais documentos? Ou seja, como balizar a leitura de um documento cuja natureza reporta a um evento traumático que, por sua própria natureza, refaz o terreno das convenções referentes à representação do passado? Pois, trata-se de uma memorização que tende a retornar ao que passou, àquilo mesmo que resistiu à significação, segundo expectativas que misturam as temporalidades, onde a divisa entre o presente e o passado torna-se nebulosa.

Antes de lançarmos respostas a tais questões, vale a pena lembrar, como proposição cautelar, que o testemunho é um dos vetores que permitem uma nova abordagem, consoante com um conceito de tempo complexo. "Nele, de um modo característico para a nossa pós-modernidade, o universal reside no mais fragmentário. Não há espaço para as verdades eternas ou para leis universais - transculturais e a-históricas"13. Trata-se, sobretudo, de um terreno onde a "memória não pode ser confundida com a realidade: onde esta não pode ser totalmente recoberta por aquela" ${ }^{14}$. Assim, parece-nos que, neste momento, mais importante do que buscar respostas é compreender, em suas múltiplas implicações, as condições de produção que operam no testemunho e as conseqüências de sua difusão.

I2 Márcio Seligmann-Silva. História, memória, literatura. O testemunho na era das catástrofes. Campinas: Editora da Unicamp, 2003 , p. 52.

I3 idem. ib. p.80.

I4 idem. ib. p.80-8I. 


\section{A Exceção é a Regra}

O filósofo Giorgio Agamben propõe uma reflexão a respeito do estado de exceção. A opção terminológica é proposital e, se Agamben utiliza o sintagma estado de exceção em vez de correlatos semelhantes como estado de sítio ou lei marcial, é porque "o estado de exceção não é um direito especial (como o direito de guerra) mas, enquanto suspensão da própria ordem jurídica, define seu patamar ou seu conceito limite" ${ }^{\text {I5 }}$. Por isso, Agamben acredita que a compreensão do estado de exceção corresponde à compreensão da "zona incerta (...) entre o político e o jurídico e entre o direito e o vivente" e que, em última instância, nos permitiria refletir sobre "o que significa agir politicamente?"

Para nós, entretanto, a problematização que o estudo do instituto estado de exceção desvela é menos pretensiosa. Trata-se, na verdade, de repensar as relações entre estados autoritários, tal como o governo militar brasileiro de I964 a I985, e estados democráticos, tal como a nova república brasileira hoje vigente. A relação diz respeito não apenas à questão da passagem de um regime democrático a um autoritário, em suposta defesa da democracia. Mas, e sobretudo, refere-se a um segundo problema: qual é o regime democrático possível após um governo autoritário que fez uso de instrumentos legais que, na prática, instauraram um estado de exceção? Daí a validade do pensamento de Agamben para o nosso trabalho, uma vez que o filósofo desenvolve ao longo de seu estudo a afirmação, cuja inspiração vem da obra de Walter Benjamin, de que o estado de exceção funcionou ao longo de todo o século XX como um paradigma de governo, inclusive naqueles estados considerados democráticos.

Tal constatação é de suma importância na medida em que procura desfazer uma oposição rígida entre um estado autoritário e um estado democrático, revelando uma série de características comuns partilhada por ambos.

Em primeiro lugar, Agamben nos lembra que "o estado de exceção é uma criação da tradição democrático-revolucionária e não da tradição absolutista"17. O estado de sítio foi criado em meio ao fervor da revolução burguesa na França, segundo decreto da Assembléia Constituinte Francesa em 8 de julho de I79I. Com o passar do tempo, o instituto foi se desvinculando da situação de guerra a qual estava ligado na origem, sendo usado, então, "como medida extraordinária

I5 Giorgio Agamben. Estado de exceção. São Paulo: Boitempo, 2004, p.I5.

I6 idem. ib. p.I2.

I7 idem. ib. p.I6. 
de polícia em caso de desordens e sedições internas, passando assim de efetivo ou militar, a fictício ou político" ${ }^{18}$.

De qualquer forma, o aparecimento do estado de exceção ao longo da história política do Ocidente, seja na teoria do direito ou em sua realização concreta, esteve comumente atrelado a um discurso salvacionista no qual a suspensão da democracia é feita em honra de sua defesa. Segundo este pensamento, uma conquista política tão elevada como a democracia demanda de seus povos qualquer sacrifício para resguardá-la - mesmo o sacrifício da própria democracia.

Percorrendo a história constitucional dos grandes Estados nacionais europeus e dos Estados Unidos, Agamben mostra o entrançamento do regime de exceção com a constituição democrática, seu uso recorrente no avanço do poder executivo sobre o legislativo. O próprio fenômeno do totalitarismo europeu não pode ser compreendido se não atentarmos às disposições constitucionais de emergência que marcam os Estados alemão e italiano em sua conformação no entre-guerras. Assim:

A Primeira Guerra Mundial - e os anos seguintes - aparecem, nessa perspectiva, como o laboratório em que se experimentaram e se aperfeiçoaram os mecanismos e dispositivos funcionais do estado de exceção como paradigma de governo. Uma das características essenciais do estado de exceção - a abolição provisória da distinção entre poder Legislativo, Executivo e Judiciário - mostra, aqui, sua tendência a transformar-se em prática duradoura de governo. ${ }^{19}$

Desta forma, o exame das democracias do primeiro mundo, após as duas guerras mundiais, evidencia que, desfeito o perigo militar real, o estado de exceção encontrou formas mais sutis de impor-se como diretriz da ação governamental. "De fato, a progressiva erosão dos poderes legislativos do Parlamento que hoje se limita, com freqüência, a ratificar disposições promulgadas pelo Executivo sob a forma de decretos com força de lei, tornou-se, desde então, uma prática comum" ${ }^{20}$. Como já havia apontado Walter Benjamin, o estado de exceção aparece como regra geral. Mais do que uma medida excepcional, o estado de exceção se apresenta como uma técnica de governo, deixando aparecer sua natureza de paradigma constitutivo da ordem jurídica.

I8 Giorgio Agamben. Estado de exceção. São Paulo: Boitempo, 2004 , p.I6.

I9 idem. ib. p.I9.

20 idem. $i b$. 
Esse deslocamento de uma medida provisória e excepcional para uma técnica de governo ameaça transformar radicalmente - e, de fato, já transformou de modo muito perceptível - a estrutura e o sentido da distinção tradicional entre os diversos tipos de constituição. ${ }^{21}$

Certamente, o exemplo mais claro e atual desse deslocamento pode ser encontrado no governo norte-americano pós II de setembro. Medidas como o USA Patriot Act normatizam o excepcional ao legalizarem a suspensão dos direitos constitucionais básicos. Ao mesmo tempo, os prisioneiros da Baía de Guantánamo não se enquadram no âmbito jurídico das leis civis ou marciais, como tampouco se restringem a fronteiras territoriais precisas. Nas palavras de Agamben, "Bush está procurando produzir uma situação em que a exceção se torne a regra e em que a própria distinção entre paz e guerra (e entre guerra externa e guerra civil mundial) se torne impossível”22.

Percebemos, portanto, como característica central do estado de exceção, a confusão entre os atos do poder executivo e os atos do poder legislativo, confusão alçada à posição de paradigma do ordenamento estatal. Daí a capacidade do poder executivo de elaborar atos com "força de lei", situação juridicamente aporética. Com efeito, um ato com "força de lei" constitui uma promulgação formal que não é lei, não possui o efeito jurídico de um ato legislativo válido. Todavia, o ato possui a "força da lei", ou seja, embora não seja lei, e mesmo contradiga o procedimento legal de elaboração legislativa, é aplicável como lei, possui sua força de realização.

Estamos, assim, diante de um problema intrínseco à constituição do direito, a saber, a cisão entre a aplicabilidade da norma e sua essência formal. A relação pode ser estabelecida em analogia à estrutura da linguagem e a arbitrariedade dos signos lingüísticos: "Como entre a linguagem e o mundo, também entre a norma e sua aplicação não há nenhuma relação interna que permita fazer decorrer uma da outra" ${ }_{23}$.

É no discurso em ato que a língua adquire denotação real, ou seja, é na atividade prática dos sujeitos falantes, apropriados da língua, que efetiva-se a passagem da semiótica a semântica, da langue a parole. Trata-se, enfim, da passagem daquilo que está no âmbito da lógica àquilo que está na esfera da práxis. No caso do direito, a norma jurídica só pode operar da lógica à práxis através

2I Giorgio Agamben. Estado de exceção. São Paulo: Boitempo, 2004, p.I3.

22 idem. ib. p.38.

23 idem. ib. p. 63 . 
do funcionamento dos corpos institucionais de um Estado que garante, após um longo "processo" e que envolve uma pluralidade de sujeitos, a efetivação real de uma sentença.

Neste sentido, o estado de exceção marca, justamente, a separação radical entre a aplicabilidade e a norma. Em outras palavras, a "força de lei" e a lei se distanciam: há uma norma em vigor cuja aplicabilidade é nula, enquanto atos sem valor de lei resguardam a força de efetivação.

O estado de exceção é um espaço anômico onde o que está em jogo é uma força de lei sem lei (que deveria, portanto, ser escrita: força de lei). Tal força de lei, em que potência e ato são separados de forma radical, é certamente algo como um elemento místico, ou melhor, uma fictio por meio do qual o direito busca se atribuir sua própria anomia. ${ }^{24}$

É neste patamar indefinido, aberto pela cisão entre a norma e sua aplicação, que o estado de exceção realiza a união possível entre a norma e a realidade. Isto significa que é necessário suspender a aplicação da norma para que esta possa ser efetivamente aplicada. É, por fim, neste espaço da exceção, onde lógica e práxis se indeterminam, que "uma pura violência sem logos pretende realizar um enunciado sem nenhuma referência real" ${ }^{25}$.

Observamos, então, a compreensão do estado de exceção como o paradigma de governo da política contemporânea. A explicitação deste entrelaçamento, aparentemente impossível, entre estado democrático e estado de exceção, e de sua lógica de funcionamento, nos parece essencial para uma crítica do presente, pois, a partir daí, parece possível tensionar as relações entre a nossa contemporaneidade democrática, a partir da qual produzimos a memória, e o nosso passado autoritário, sobre o qual produzimos a memória. Desta forma, tal perspectiva de análise parece apontar para um horizonte donde seria possível entender a história política do período sem recorrer a uma oposição estanque entre a ditadura e estado de direito. Trata-se de uma perspectiva que possibilita um olhar sobre as relações profundas que marcam o período da ditadura e o da consolidação da nossa democracia, sem que com isso sejamos levados a relativizar suas diferenças.

24 Giorgio Agamben. Estado de exceção. São Paulo: Boitempo, 2004, p.6I.

25 idem. ib. p.63. 


\section{Referências Bibliográficas}

Agamben, Giorgio. Estado de exceção. São Paulo: Boitempo, 2004.

Benjamin, Walter. Obras escolhidas. v I. 3 ed. São Paulo: Editora Brasiliense, 1987.

CARdoso, Irene. Para uma crítica do presente. São Paulo: Editora 34, 200 I.

Foucault, Michel. Doença mental e psicologia. Rio de Janeiro: Tempo Brasileiro, I975.

Grespan, Jorge Luis. "O lugar da história em tempos de crise". In: http:// www. anpuh.uepg.br/historia-hoje/vol2n5/Jorge.htm

Seligmann-Silva, Márcio. História, memória, literatua. O testemunho na era das catástrofes. Campinas: Editora da Unicamp, 2003.

EDUARDO Zayat Chammas é graduando em história pela USP e bolsista pelo PET.

E-mail: educhammas@hotmail.com.

GABRIEL Ferreira Zacarias é graduando em história pela USP e bolsista pelo PET.

E-mail: gabrielzacarias@gmail.com.

TIAGO Machado de Jesus é graduado em história pela USP.

E-mail: tiagomach@uol.com.br. 